\title{
THE FLUID-LIKE AND CRITICAL BEHAVIOR OF THE ISOTROPIC-NEMATIC TRANSITION APPEARING IN LINEAR AND NON-LINEAR DIELECTRIC STUDIES
}

\author{
A. Drozd-Rzoska, S.J. Rzoska and J. Zlolo \\ August Chełkowski Institute of Physics, Silesian University \\ Uniwersytecka 4, 40-007 Katowice, Poland
}

\begin{abstract}
A short review of literature and the authors' experimental results for the pretransitional behavior in the isotropic phase of nematogens is given. The paper also presents new results of non-linear dielectric effect and dielectric permittivity measurements in the broad temperature range. Results obtained show significant advantages of non-linear dielectric effect and dielectric permittivity for studying pretransitional properties in liquid crystalline materials. The paper contains a comprehensive comparison of the experiment with predictions of the mean-field model and the fluid-like description. The presented analysis strongly supports the image of the isotropic phase as a complex liquid resulting from vicinity of the fluid-like, "nematic-isotropic", critical point.
\end{abstract}

PACS numbers: $64.70 . \mathrm{Md}, 64.30 .+\mathrm{t}, 77.22 . \mathrm{Ch}$

\section{Introduction}

On approaching the nematic clearing temperature $\left(T_{\mathrm{I}-\mathrm{N}}\right)$ a series of physical properties exhibit a strong pretransitional increase, proportional to $\left(T-T^{*}\right)^{-1}$, where $T>T_{\mathrm{I}-\mathrm{N}}$ and $T^{*}=T_{\mathrm{I}-\mathrm{N}}+\Delta T$ : the temperature $T^{*}$ denotes the extrapolated temperature of a hypothetical continuous phase transition and $\Delta T$ is the measure of the discontinuity of the transition [1-7]. These properties include: the intensity of the scattered light $\left(I_{\mathrm{L}}\right)$ [8-10] , the Cotton-Mouton effect (CME) [11-13], the optical Kerr effect (OKE) [14-16], the electrooptic Kerr effect (EKE) [17-19], the turbidity $(t)$ [20], the non-linear dielectric effect (NDE) [21-25], relaxation time of pretransitional processes $(\tau)[15,16,26]$, the square of NMR linewidth [27], thermal expansion coefficient and compressibility $\left(\alpha_{\mathrm{p}}, \chi\right)$ [28]. The parametrization of these anomalies made the application of mean field based models possible, such as the Maier-Saupe model [29] or the Landau-de Gennes (LdG) model [1]. Particularly the latter has been broadly explored in the isotropic 
phase due to its simplicity (see Refs. above). However, there is long-standing evidence of a limited consistency between mean-field based models and the experiment $[1,2,30,31]$. The most puzzling fact is the discrepancy between the theoretically predicted values of transition discontinuity and the experimental ones $[1,31]$. Experiments mentioned above showed a weakly discontinuous character of the I-N transition with $\Delta T_{\mathrm{Exp}}=0.5-2 \mathrm{~K}$. Significant efforts led to the reduction of the calculated value of $\Delta T_{\text {Theor. }}$ from about $40 \mathrm{~K}$ to $7 \mathrm{~K}[1-7,31-34]$. The first to mention the problem of the mean-field approximation was probably de Gennes in his monograph in 1974 [1]. He also wondered what the reason was for such a different behavior of the intensity of scattered light in the isotropic phase $\left(I_{\mathrm{L}} \propto\left(T-T^{*}\right)^{-\gamma}, \gamma=1\right)$ and for the gas-liquid critical point or critical consolute point $\left(I_{\mathrm{L}} \propto\left(T-T_{\mathrm{C}}\right)^{-\gamma}, \gamma=1.23\right)[1]$. It is noteworthy that a similar problem arises for EKE and NDE: in the isotropic phase NDE, $\mathrm{EKE} \propto\left(T-T^{*}\right)^{-\gamma}, \gamma=1$ whereas in critical mixtures $\mathrm{EKE} \propto\left(T-T_{\mathrm{C}}\right)^{-\psi_{\mathrm{EKE}}}, \psi_{\mathrm{EKE}}=0.59-0.85$ and $\mathrm{NDE}$ $\propto\left(T-T_{\mathrm{C}}\right)^{-\psi_{\mathrm{NDE}}}, \psi_{\mathrm{NDE}} \approx 0.4$ or $\psi_{\mathrm{NDE}} \approx 0.59[35-37]$.

When discussing problems of mean-field models in the isotropic phase of nematogens it is worthy pointing to the significant inconsistencies between predictions of the Maier-Saupe and Landau-de Gennes models.

Within the mean-field approximation there is no anomaly of physical properties associated with the exponent $\alpha$ in the high temperature phase: the exponent $\alpha=0$. However, experiments clearly show the pretransitional anomaly of physical properties associated with the critical exponent $\alpha[4,38-46]$

$$
\begin{aligned}
& \rho(T)=d_{1}+d_{2}\left(T-T^{*}\right)+D\left(T-T^{*}\right)^{1-\alpha}, \\
& c_{P}(T)=a_{1}+a_{2}\left(T-T^{*}\right)+a_{3}\left(T-T^{*}\right)^{2}+A\left(T-T^{*}\right)^{-\alpha},
\end{aligned}
$$

where $\rho(T)$ and $c_{P}(T)$ are the density and the specific heat respectively. Coefficients $d_{i}, a_{i}, D$, and $A$ denote amplitudes.

Unfortunately, there are no conclusive results for the value of exponent $\alpha$ so far. For instance, a reasonable fit could be reached for $\alpha=0.5-0.11$, with a flat minimum around 0.4 for a specific heat $[4,42,43]$. This uncertainty can be related to the minute scale of anomalies, their limited range of appearance $\left(T-T_{\mathrm{I}-\mathrm{N}}<4 \mathrm{~K}\right)$ and the discontinuity of the I-N transition. However, recently an agreement between the theory and the experiment has been reached due to the concept of fluid-like, critical behavior in the isotropic phase of nematogens $[22,24,31,47,48]$. The theoretical model proposed by Mukherjee et al. [31, 47, 48] did not only give reasonable values of $\Delta T$, but also predicted a non-zero value of the critical exponent $\alpha=0.5$ in the isotropic phase. Recent linear (dielectric permittivity) and non-linear dielectric studies led to significant new experimental results supporting the fluid-like hypothesis [22-25]. The application of the LdG model for NDE gave [22, 25, 49]:

$$
\mathrm{NDE}=\frac{A_{\mathrm{NDE}}}{\left(\mathrm{T}-\mathrm{T}^{*}\right)^{\gamma}}=\frac{2}{3 a} \varepsilon_{0} \frac{\Delta \varepsilon^{f} \Delta \varepsilon^{0}}{T-T^{*}},
$$

where $\Delta \varepsilon^{f}$ is the anisotropy of dielectric permittivity for a given frequency of a weak measuring field, the coefficient $a$ denotes the constant amplitude containing in the second rank term in the LdG series the free energy density. 
In the static, low-frequency limit $(f \rightarrow 0)$ this relation is simplified to

$$
\mathrm{NDE}=\frac{2}{3 a} \varepsilon_{0} \frac{\left(\Delta \varepsilon^{0}\right)^{2}}{T-T^{*}}
$$

In leading monographs the I-N transition is presented as an example of the validity of the mean-field behavior despite the problems mentioned above. This statement is often supported by results already obtained in the seventies for $I_{\mathrm{L}}, \mathrm{CME}, \mathrm{KE}$ [7-10]. The reciprocal of these properties is a linear function of temperature usually up to $5-10 \mathrm{~K}$ from $T_{1-\mathrm{N}}$. In the immediate vicinity of the clearing temperature weak distortion from such dependence appears. Some problems introduce the necessity of considering the additional, non-pretransitional, background term $[4,8-10,13,14]$. The behavior of low frequency (LF) NDE is unique particularly bearing in mind that the same behavior is observed both for the $\mathrm{I}-\mathrm{N}$ and isotropic to smectic $\mathrm{A}$ and smectic $\mathrm{E}$ transitions $[50,51]$. The latter feature definitively does not take place for $\mathrm{KE}, \mathrm{CME}, I_{\mathrm{L}}[4,8-10,13,14]$. The reciprocal of NDE is linear functions of temperature up to $T_{\mathrm{X}} \approx T_{\mathrm{I}-\mathrm{N}}+40 \mathrm{~K}$ from the clearing point. This temperature may be considered as the place where fluctuations shrink to about 3 molecules $[25,52,53]$. Additionally, there is no background term and there are no discrepancies near $T_{\mathrm{I}-\mathrm{N}}$ from linearity of the NDE reciprocal [25]. All this significantly increases the reliability of the determined values of $\Delta T$. The pretransitional behavior is also observed for the static dielectric permittivity if the permanent dipole moment lies along the long axis of the molecule. This takes place, for instance, in $n$-cyanobiphenyls. Hence $\varepsilon(T)$ registers the changes of dielectric permittivity due to the cancellation of the prenematically ordered permanent dipole moments. The obtained dependencies are parameterized by $[24,25,50,51]$ :

$$
\varepsilon(T)=\varepsilon^{*}+a_{\varepsilon}\left(T-T^{*}\right)+A_{\varepsilon}\left(T-T^{*}\right)^{1-\alpha}, \quad \alpha=0.5 \pm 0.02 .
$$

Figure 1 shows the behavior in the isotropic phase for the static NDE and dielectric permittivity for 4-cyano-4-pentyl-alkoxybiphenyls (5CB) in a broad temperature range up to $T_{\mathrm{I}-\mathrm{N}}+80 \mathrm{~K}$. The descriptions of experimental setups are given in detail in our previous papers $[50,51]$. It is noteworthy that $\varepsilon(T)$ is parameterized in the whole temperature range. Figure 2 shows the derivative of experimental data from Fig. 1.

This very sensitive analysis shows that relation (3) for NDE is valid only up to about $T_{\mathrm{X}} \approx T^{*}+40 \mathrm{~K}$. The inset made it possible to claim that there is definitively no discrepancies from relation (5) in the whole tested range, also above $T_{\mathrm{X}}$. However, above $T_{\mathrm{X}}$ the prenematic ordering may take place in group of molecules which effectively contain less than 2 molecules and hence are too small to be recognized as a fluctuation by the fluctuation-sensitive method (for instance: NDE). Figures 1 and 2 made possible a reliable estimation of critical exponents: $\gamma=1$ and $\alpha=0.5 \pm 0.02$.

It is noteworthy that Eqs. (3), (4) can also be derived beyond the LdG approximation, basing on relations for critical mixtures [23-25]: 
$\mathrm{NDE}, \mathrm{EKE} \propto\left\langle\Delta M^{2}\right\rangle_{V} \chi \approx\left\langle\Delta M^{2}\right\rangle_{V} \cdot \chi_{0} /\left(T-T_{\mathrm{C}}\right)$ (critical mixtures) $\rightarrow$

$\mathrm{NDE}, \mathrm{EKE} \propto\langle\Delta M\rangle_{V}^{0}\langle\Delta M\rangle_{V}^{f} \cdot \chi_{0}^{*} /\left(T-T^{*}\right) \propto \Delta \varepsilon^{f} \Delta \varepsilon^{f} /\left(T-T^{*}\right)$

(nematogens),

where $\left\langle\Delta M^{2}\right\rangle_{V}$ denotes the mean square of the order parameters. The presented approximation is possible because prenematic fluctuations are naturally elongated and almost non-interacting.

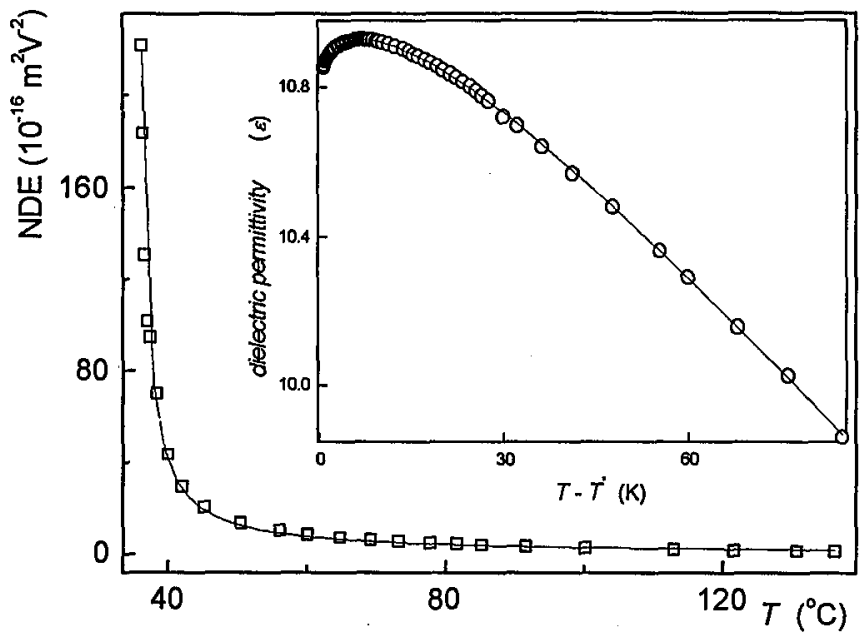

Fig. 1. Results of NDE and dielectric permittivity measurements in the isotropic phase of $5 \mathrm{CB}$. The measurement frequency of NDE was $62 \mathrm{kHz}$ and the frequency of dielectric permittivity was $10 \mathrm{kHz}$.

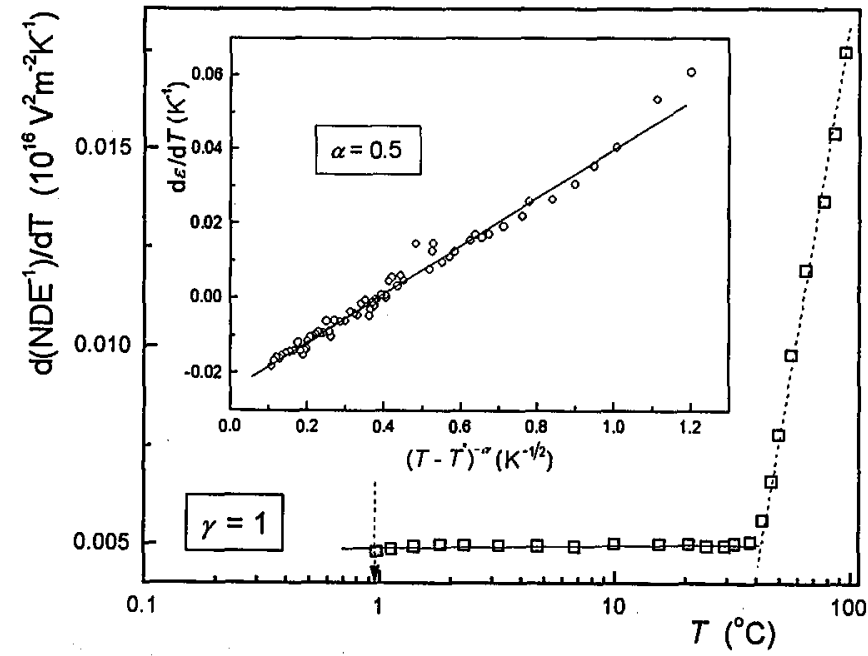

Fig. 2. Results of differential analysis of experimental dielectric permittivity and NDE in $5 \mathrm{CB}$ from Fig. 1. 
TABLE

The comparison of predictions of mean-field approximation and the fluid-like description with experimental results.

\begin{tabular}{|c|c|c|}
\hline \multirow{2}{*}{$\begin{array}{l}\text { Experimental results } \\
\quad \text { for } T \rightarrow T_{\mathrm{I}-\mathrm{N}}\end{array}$} & \multicolumn{2}{|c|}{ Agreement with experiment } \\
\hline & mean-field description & fluid-like description \\
\hline exponent $\gamma=1$ & Yes & Yes \\
\hline $\begin{array}{l}\text { parametrization of } \\
\chi \text {-related properties } \\
(\mathrm{KE}, \mathrm{NDE}, . .)\end{array}$ & Yes & Yes \\
\hline exponent $\alpha=1 / 2$ & No & Yes \\
\hline $\begin{array}{l}\text { parametrization of the } \\
\text { specific heat, density, di- } \\
\text { electric permittivity }\end{array}$ & No & Yes \\
\hline $\begin{array}{l}\text { small value of the transi- } \\
\text { tion discontinuity }\end{array}$ & No & Yes \\
\hline $\begin{array}{l}\text { "de Gennes question": re- } \\
\text { lationship to critical mix- } \\
\text { tures etc. }\end{array}$ & No & Yes \\
\hline $\begin{array}{l}\text { dynamic critical exponent } \\
z=2[54]\end{array}$ & No & Yes \\
\hline $\begin{array}{l}\text { dispersion dependence of } \\
\text { the apparent } A_{\mathrm{NDE}}(\mathrm{T}, \mathrm{P}) \\
\text { amplitude }[54]\end{array}$ & No & Yes \\
\hline $\begin{array}{l}\text { dependence of } A_{\mathrm{NDE}} \text { on } \\
\text { the intensity of the weak } \\
\text { measuring field [54] }\end{array}$ & No & Yes \\
\hline $\begin{array}{l}\text { application for NDE and } \varepsilon \\
\text { in smectogens }[50,51]\end{array}$ & No & Yes \\
\hline dimensionality & $d=4$ & $d=3$ \\
\hline
\end{tabular}

It should be mentioned here that differences in the behavior of EKE and NDE in critical mixtures is associated with the classical-nonclassical properties of fluctuations elongated in the strong electric field which have a different influence on NDE and EKE [36, 37].

The above analysis answers the mentioned "de Gennes problem" ([1], 1974). It also shows that the pretransitional amplitude of NDE is associated with fluctuations of the order parameters. This fact is significant when analyzing $\operatorname{NDE}(T)$ for frequencies coinciding with the relaxation time of pretransitional processes as shown in Fig. 2. The strong discrepancies near $T_{\mathrm{I}-\mathrm{N}}$ can be treated as the consequence of the relation between the timescale introduced by the measurement frequency and the relaxation time. Additional distortion in the immediate vicinity 
of $T_{\mathrm{I}-\mathrm{N}}$ may be related to the consequence of the sensitivity to the intensity of the weak measuring field. Such sensitivity agrees with the complex liquid nature of the isotropic phase. It is noteworthy that remotely from $T^{*}$, where $f^{-1} \gg \tau$, the presented effect follows the LF NDE pattern.

The mentioned three-decades success of the mean-field description was due to the lack of alternative proposals. In the opinion of the authors the idea of a fluid-like, critical description may be treated as such an alternative proposal. In this case temperature $T^{*}$ can be identified as the pseudospinodal, critical Gaussian point or the pseudospinodal tricritical point $[25,54]$. To support the fluid-like idea we present the first comprehensive comparison between theory and experiment (Table). Concluding, it is also noteworthy that linear and non-linear dielectric investigation deliver a set of new experimental data, which were not available by other experimental methods mentioned above [22-25, 50, 51].

\section{Acknowledgments}

The authors would like to acknowledge the support of the Committee for Scientific Research grant no. 2PO3B 02015.

\section{References}

[1] P.G. de Gennes, The Physics of Liquid Crystals, Clarendon Press, Oxford 1974; P.G. de Gennes, J. Prost, The Physics of Liquid Crystals, Clarendon Press, Oxford 1993.

[2] F.H. Gramsbergen, L. Longa, W.H. de Jeu, Phys. Rep. 135, 195 (1986).

[3] G. Vertogen, W.H. de Jeu, Thermotropic Liquid Crystals, Fundamentals, Springer Series in Chemical Physics, Springer-Verlag, Berlin 1988.

[4] M.A. Anisimov, Critical Phenomena in Liquid and Liquid Crystals, Gordon and Breach, Philadelphia 1993.

[5] S. Chandrasekhar, Liquid Crystals, Cambridge Univ. Press., Cambridge 1994.

[6] Handbook of Liquid Crystals, Vol. 1, Fundamentals, Eds. D. Demus, J. Goodby, G.W. Gray, H.W. Spiess, V. Vill, Wiley-VCH, Weinheim 1998.

[7] S. Singh, Phys. Rep. 324, 107 (2000).

[8] T.W. Stinson, J.D. Litster, Phys. Rev. Lett. 30, 688 (1973).

[9] H. Zink, W.H. de Jeu, Mol. Cryst. Liq. Cryst. 124, 287 (1985).

[10] J. Fuchs, W. Burchard, J. Phys. II (France) 4, 1451 (1994).

[11] P.G. de Gennes, Phys. Lett. A 30, 454 (1969).

[12] P.G. de Gennes, Mol. Cryst. Liq. Cryst. 12, 193 (1971).

[13] K.-I. Muta, H. Takezoe, A. Fukuda, E. Kuze, Jpn. J. Appl. Phys. 8, 2073 (1979).

[14] D.A. Dunmurr, E. Tomes, Mol. Cryst. Liq. Cryst. 76, 231 (1981).

[15] H.J. Coles, Chem. Phys. Lett. 59, 168 (1978).

[16] R. Yamamoto, S. Isihara, S. Hayakawa, K. Morimoto, Phys. Lett. A 69, 276 (1978).

[17] W. Pyżuk, I. Słomka, J. Chrapeć, S.J. Rzoska, J. Zioło, Chem. Phys, 121, 255 (1988). 
[18] L.K. Schneider, J.H. Weindorf, Liquid Crystals 22, 2 (1997).

[19] J.H. Yi, Ch.-Ho Cho, J.H. Lee, J.-S. Chang, J. Phys. Korean Soc. 23, 7 (1990).

[20] W.J. Lin, P.H. Keyes, W.B. Daniels, J. Phys. (France) 41, 633 (1980).

[21] J. Małecki, J. Zioło, Chem. Phys. 35, 187 (1978).

[22] A. Drozd-Rzoska, S.J. Rzoska, J. Zioło, Liquid Crystals 21, 273 (1996).

[23] A. Drozd-Rzoska, S.J. Rzoska, J. Zioło, Phys. Rev. E 55, 2881 (1997).

[24] A. Drozd-Rzoska, S.J. Rzoska, J. Zioło, Phys. Rev. E 55, 6452 (1997).

[25] A. Drozd-Rzoska, Phys. Rev. E 59, 5556 (1999).

[26] P.V. Kolynski, B.R. Jennings, Mol. Phys. 40, 979 (1980).

[27] R.Y. Dong, E. Tomchuk, J.J. Visintainer, E. Bock, Mol. Cryst. Liq. Cryst. 33, 101 (1976).

[28] J. Bendler, Mol. Cryst. Liq. Cryst. 38, 19 (1977).

[29] G.S. Attardand, G.R. Luckhurst, Liquid Crystals 2, 441 (1987).

[30] L. Senbetu, Chia-Wei Woo, Mol. Cryst. Liq. Cryst. 84, 101 (1982).

[31] P.K. Mukherjee, J. Phys., Condens. Matter 10, 9191 (1998).

[32] W. Maier, R. Saupe, Z. Naturforsch. 14, 882 (1959).

[33] Y.S. Mingh, H.M. Huang, Ch.-W. Woo, Mol. Cryst. Liq. Cryst. 24, 7 (1976).

[34] R.G. Priest, Mol. Cryst. Liq. Cryst. 42, 223 (1976).

[35] S.J. Rzoska, A. Drozd-Rzoska, J. Zioło, Phys. Rev. E 61, 960 (2000).

[36] S.J. Rzoska, Phys. Rev. E 48, 1136 (1993).

[37] S.J. Rzoska, V. Degiorgio, M. Giardini, Phys. Rev. E 49, 5234 (1994).

[38] E. Gulari, B. Chu, J. Chem. Phys. 62, 795 (1975).

[39] G. Koren, Phys. Rev. A 13, 1177 (1976).

[40] D. Armitage, F.P. Price, Mol. Cryst. Liq. Cryst. 38, 229 (1977).

[41] E.A.S. Lewis, H.M. Strong, G.H. Brown, Mol. Cryst. Liq. Cryst. 53, 89 (1979).

[42] J. Thoen, W. Marynissen, W. Van Dael, Phys. Rev. A 26, 2886 (1982).

[43] H. Marynissen, J. Thoen, W. Van Dael, Mol. Cryst. Liq. Cryst. 97, 149 (1983).

[44] G.A. Oweimreen, A.K. Shihab, K. Halhouli, S.F. Sikander, Mol. Cryst. Liq. Cryst. 138, 327 (1986).

[45] R.A. Orwoll, V.J. Sullivan, G.C. Campbell, Mol. Cryst. Liq. Cryst. 149, 121 (1987).

[46] R. Kiefer, G. Baur, Mol. Cryst. Liq. Cryst. 188, 13 (1990).

[47] P.K. Mukherjee, T.B. Mukherjee, Phys. Rev. B 52, 9964 (1995).

[48] P.K. Mukherjee, M. Saha, Phys. Rev. E 51, 5745 (1995).

[49] S.J. Rzoska, J. Zioło, Liquid Crystals 17, 629 (1994).

[50] A. Drozd-Rzoska, S.J. Rzoska, J. Zioło, Phys. Rev. E 61, 5349 (2000).

[51] A. Drozd-Rzoska, S.J. Rzoska, K. Czupryński, Phys. Rev. E 61, 5355 (2000).

[52] A. Sengupta, M.D. Fayer, J. Chem. Phys. 102, 4193 (1995).

[53] R. Torre, F. Tempestini, P. Bartolini, R. Righini, Philos. Mag. A 77, 645 (1997).

[54] A. Drozd-Rzoska, Liquid Crystals 24, 835 (1998). 